\title{
ENTREVISTA COM O POETA EXPERIMENTAL ERIESTO MANUEL de MELo E CASTRO
}

http://dx.doi.org/10.11606/issn.2175-3180.v13i24p29-52*

Por Ana Cristina Joaquim ${ }^{\mathrm{I}}$

ANA CRISTINA JOAQUIM: Ernesto, começo essa conversa trazendo um dado da sua biografia que acaba por resultar numa metáfora da sua atuação poética: profissional de engenharia têxtil e tendo ministrado cursos de tecnologia na área, você propõe um diálogo entre a tecnologia e a criação textual (textum: tecido...). Considerando que você foi um dos pioneiros no uso da diversidade de mídias com finalidades literárias em Portugal, em que medida você diria que a tessitura da palavra foi se fazendo em diálogo com a tecnologia no seu percurso criativo?

ERNESTO MANUEL DE MELO E CASTRO: É um fato insofismável que a minha vida se deu entre o tecido e o texto! Para responder à sua pergunta vou recuperar um texto já com alguns anos em que tento estabelecer os modos como sinto essa dualidade. Acontece que o aspecto têxtil é uma coisa importante, porque o têxtil não é inocente. Eu fui conduzido para a engenharia têxtil por razões imediatas, pela necessidade de tirar um curso, pela necessidade de ter uma profissão; eu tinha passado por três anos de boêmia em Lisboa, pretendendo estar a frequentar um curso de medicina para o qual não tinha nenhuma vocação e a única coisa que eu fazia na

\footnotetext{
* Publicada originalmente na revista Desassossego, v. 5, n. 9, jun/2013:

https://www.revistas.usp.br/desassossego/issue/view/4249

DOI original: https://doi.org/10.11606/issn.2175-3180.v5i9p181-197

I Universidade de São Paulo, São Paulo, Brasil.
} 
Faculdade de Medicina era ler poemas, nos intervalos das aulas, para os meus colegas; eu não ia às aulas, ia aos intervalos das aulas; de fato, foi um equívoco essa estória da medicina e fui confrontado com a necessidade de ganhar a vida... A minha família tinha uma fábrica têxtil e, portanto, fui para a fábrica têxtil que eu conhecia como aos meus dedos desde criança, onde eu tinha brincado, enfim, o ambiente da fábrica têxtil era-me extremamente familiar e eu rapidamente vi que poderia ser um engenheiro têxtil. Fui para Inglaterra estudar engenharia têxtil e dei-me muitíssimo bem. Gostei muito do curso, identifiquei-me imediatamente com a matéria, principalmente nos seus aspectos produtivos, isto é a fabricação desde o fio ao tecido. Na altura em que eu tirei o curso (anos 50), ainda não havia a automação, mas havia a mecanização, ou seja, já não se fiava nem tecia à mão. Mas nas fábricas havia as fiações e os teares mecânicos e começava a haver mecanismos primários de automação mecânica de algumas funções. Portanto as operações eram mais lentas do que hoje são, as operações, sendo por isso mais rituais, digamos assim. A mim, fascinava-me ver como o fio se enrolava nas bobinas dispostas em séries. Era uma coisa estética que me fascinava, o olhar para aquela repetição das bobinas rodando, rodando... Enrolando o fio que ia sendo produzido! Era um movimento sem fim... E talvez tivesse sido ali que eu apreendi a voluptuosidade do movimento. Também na tecelagem - à qual me dediquei, porque sou engenheiro têxtil de produção de tecidos, não de fiação -, na tecelagem, a coisa ia muito mais longe, porque a máquina de tecer é uma máquina milenar, mas o processo é basicamente o mesmo, quer nos teares manuais como nos teares mais automáticos, mais avançados, e mais rápidos e mais eficientes e perfeitos que hoje há: tecem com a mesma técnica milenar de levantar uns fios, baixar outros e passar no meio um fio. Depois os que sobem descem, os que descem sobem, ou segundo uma outra ordem pré-determinada. Este processo da tecelagem é um processo que me fascinava e me fascina ainda hoje. É que eu sei tecer em qualquer tipo de tear com grande eficiência e grande voluptuosidade até, porque olhando para o local onde o tecido se forma vejo ali um movimento absolutamente genésico. É um nascimento! É qualquer coisa nova e diferente que nasce: o tecido é por isso, uma metáfora do nascimento. Por outro lado, como já disse, a abertura da diferença entre os fios que sobem e os fios que descem (que em terminologia portuguesa se chama "cala") é a essência da tecelagem. Mas essa "cala" é uma vagina! Dali é que nasce o tecido. Ora, todo o trabalho da 
tecelagem é um trabalho ligado à produção de qualquer coisa, ao nascimento de qualquer coisa que se gasta e se renova. São os tecidos que se destinam a ser usados, a ser efêmeros e a gastarem-se, cumprindo três tipos de funções: a que chamamos função social representativa, a função pragmática de vestuário e proteção, e a função estética, formando um triângulo semiótico no qual se representa toda a vida humana. Por isso a moda não é uma coisa supérflua. Só é efêmera porque passa, mas o fenômeno da moda não passa. Antes se renova ciclicamente. Por outro lado, o têxtil tem um aspecto, como já disse, criativo e genésico que se faz extremamente sexualizado, porque a fiação faz-se em fusos que rodam e esses fusos são falos... E a tecelagem é extremamente feminina; por isto, na antigüidade a tecelagem era feita por mulheres. A tecelagem só passou a ser feita por homens quando os teares se tornaram máquinas muito pesadas e ruidosas. Mas quando os teares são automatizados e atualmente robotizados, quando os teares se tornam máquinas extremamente sofisticadas, voltam as mulheres à tecelagem, como supervisoras; e todo o trabalho de tecelagem é um trabalho ligado à mulher.

Como é que isto tudo se articula com a arte da poesia? -É que em todo este complexo processo, os tecidos, cada tecido, conta uma história, ou melhor, é uma estória! É um texto escrito num outro código em que a visualidade e o tato são usados significativa e voluptuosamente! Penso e sinto que já deixei aqui alguns elementos interessantes para podermos considerar que, como diz Sadie Plant, no livro Mulher Digital, os próprios têxteis são de uma maneira bem literal os softwares fundamentais de toda a tecnologia, acompanhando o Homem desde os seus primórdios. Mas deve também ser notado que a primeira Revolução Industrial é na indústria têxtil que se manifesta. E as transformações sociais realmente básicas são feitas através do software têxtil. A primeira máquina 'cibernética' comandada no sistema hoje chamado "digital" é o tear Jacquard, inventado no século XVIII pelo francês Jacquard, usando pela primeira vez cartões perfurados antecessores dos que depois vieram a ser usados nos primeiros computadores. O tear Jacquard serve para tecer grandes desenhos pois permite comandar independentemente um número elevado de fios da teia, uns subindo e outros descendo. Mas também o uso do sistema binário de zeros e um já estava implícito nos cartões perfurados, tendo as perfurações um significado (fios de teia que sobem) sendo a falta de perfurações correspondentes a fios da teia que descem. Assim se faz a abertura da 'cala' 
por onde passa a trama, operação que como já disse, origina o tecido. Antigamente, esses fios que subiam e desciam eram comandados um a um por crianças empoleiradas no alto do tear, puxando os fios com umas argolinhas. Essas crianças foram substituídas pelos cartões perfurados e por isso se revoltaram contra a fábrica do Sr. Jacquard, destruindo-a parcialmente, porque perderam o emprego. Jacquard fugiu para Inglaterra onde foi bem recebido e então sua indústria têxtil prosperou, no início da Revolução Industrial. De fato o tear Jacquard é uma máquina realmente inovadora que vem ao encontro da máquina de calcular de Babage, e das máquinas de relojoaria, indo ao encontro de todos os sistemas de automedição, automatização e dos comandos mecânicos pré-cibernéticos, que são característicos do século XIX. Portanto, os têxteis representaram para mim uma iniciação. Eu acho que no meu trabalho como engenheiro têxtil (e devo dizer que fui engenheiro têxtil ativo durante quarenta anos, visto que comecei em 1956 - na vida prática como engenheiro têxtil - e terminei em 1996). Fiz de tudo: passei por todas as escalas profissionais da indústria têxtil e obviamente acabei na pedagogia têxtil. Escrevi vários livros, porque sou também um produtor de livros, e estou ligado realmente de uma forma muito orgânica, quer à tecnologia quer à escrita da poesia. Nunca fiz diferença entre o meu trabalho com verso, prosa, poema visual ou poema cibernético, tal como nunca fiz diferença entre o meu trabalho têxtil e o meu trabalho poético; sempre os considerei como dois trabalhos complementares e nunca contraditórios. Quando me perguntavam: "como é que consegue conciliar tudo?". Eu respondia: “Não sei!". Mas sempre consegui. Hoje sei que a chave é eu não considerar este trabalho em compartimentos aparte e como antagônico, mas sim como modos da invenção. Por outro lado, o trabalho com a poesia visual é o que mais se aproxima do trabalho com o desenho têxtil, nos princípios, nos métodos, nos materiais - hoje todo desenho têxtil é feito em computador, já não se faz desenho têxtil à mão, em parte nenhuma. Portanto, eu fui pioneiro do desenho têxtil feito em computador em Portugal, tal como fui da infopoesia! Acho que esta complementaridade é, digamos, substancial, orgânica, profunda e a quem, por vezes, me diz: "és um mau poeta porque és engenheiro" ou "és um mau engenheiro porque és poeta", para esses sempre tive e terei uma única resposta: uma enorme gargalhada!!

ACJ: Aqui no Brasil, a partir dos anos 50, os poetas Augusto de Campos, 
Haroldo de Campos, Décio Pignatari, José Lino Grünewald e Ronaldo Azeredo apresentaram uma proposta de integração entre as esferas sonoras, visuais e verbais, sintetizada no projeto verbivocovisual, que apresenta, em linhas gerais, as diretrizes do Movimento Concretista. Em Portugal, a Poesia Experimental, que desponta na década de 60, manteve algum diálogo com os poetas concretistas?

EMMC: Sim, e foram diálogos muito importantes e cordiais, ao longo de muitos anos! Não me recordo bem como pela primeira vez tive conhecimento do trabalho de Haroldo de Campos, possivelmente através de Alberto da Costa e Silva que nos anos finais da década de 50 pertencia à Embaixada do Brasil em Portugal. Mas lembro-me muito bem da publicação de uma pequena antologia da Poesia Concreta por ele então realizada. Essa publicação foi muito bem recebida em Lisboa, principalmente pelos poetas jovens que nós então éramos e que logo a seguir estabelecemos vários contatos com os poetas brasileiros, tendo eu publicado em 1962 o livro de poesia concreta IDEOGRAMAS. Então, a correspondência começou a fluir nos dois sentidos principalmente com o envio de publicações, livros, artigos de jornal, revistas, folhetos, que em ambos os lados do Atlântico íamos produzindo. As cartas eram raras, mas as dedicatórias são bem ilustrativas de um mútuo apreço. Comentando este fato Haroldo de Campos numa entrevista que com ele realizei mais tarde, por ocasião de uma das suas passagens por Lisboa em 1973: ... a carta “é um meio ultrapassado. Eu acho que se nós pudéssemos comunicar diretamente por rádio seria uma conversa diária. Mas a carta é realmente uma certa resistência, é muito artesanal demais para nós que somos homens de um tempo mais tecnológico!"... Evidentemente, a Internet não existia ainda, mas nós já lhe sentíamos a falta! Em 1966 eu viajei para o Brasil com um convite da Embaixada do Brasil em Lisboa, para conhecer pessoalmente poetas Brasileiros, tendo dividido três semanas entre São Paulo, Rio e Belo Horizonte. Então contatei com todos os poetas concretos incluindo Edgar Braga e Pedro Xisto, mas também Affonso Ávila e o contista Murilo Rubião, e alguns jovens poetas. Mas uma "rede" de comunicações inter-concreta (podemos chamá-la assim) via correio aéreo internacional estava já em pleno desenvolvimento durante toda a década de 60, entre poetas concretos de todo o mundo. O poeta experimental Don Sylvester Houèdard, UK "monge beneditino, budista e poeta concreto" 
como ele gostava de se apresentar, tinha até um grosso caderno de endereços de poetas concretos e para- concretos de muitos países, nomeadamente do Leste Europeu que emprestava para consulta e cópia a quem estivesse interessado! Ele desempenhou, durante aqueles anos 60 e 70 , o papel de distribuidor de informação, além do extraordinário poeta que era. Essa rede consistia na troca de livros, revistas, pôsteres, bilhetes, poemas-objeto, desdobráveis, jornais, fotos, etc., etc., de poemas e artigos experimentais e concretos. A minha coleção internacional com cerca de 350 itens encontra-se hoje bem preservada, mas aberta para consulta de estudantes, na biblioteca do Museu de Arte Moderna da Fundação de Serralves, na cidade do Porto, em Portugal. Todo esse intercâmbio que nunca foi subsidiado por ninguém, foi, no entanto, muito implementado por um fato insólito: no dia 25 de Maio de 1962, o Suplemento Literário do Times, de Londres, publicou a seguinte carta, na secção de Cartas dos Leitores, que traduzo a seguir:

\section{Senhor Diretor}

Li com muito interesse o artigo "Poesia, Prosa e a Máquina" de um correspondente especial, publicado no número de 4 de Maio do seu jornal, mas não posso deixar de ficar surpreendido por ele não ter mencionado o cada vez mais importante movimento da Poesia Concreta que, sendo oriundo do BRASIL, chega agora a Portugal. De fato, a Poesia Concreta é uma bem sucedida experiência de escrita ideogramática ou diagramática e também de criação poética, precisamente nas linhas referidas pelo seu correspondente.

Este tipo de experiência propõe-se substituir o método tradicional da comunicação descritiva por um modo visual compacto e ideogramático de criar e comunicar relações complexas e sutis entre idéias, imagens, palavras, coisas, etc.. A Poesia Concreta está a despertar uma onda de interesse tanto no Brasil como em Portugal, especialmente entre os jovens e os mais avançados poetas.

E.M. de Melo e Castro Estrada da Floresta nำ18

Covilhã Portugal

Alguns anos mais tarde, soube-se que o referido artigo do TLS que tinha sido publicado sem indicação do autor como era regra nesse jornal, era da autoria de Herbert Read, o mais notável crítico de artes visuais do Reino Unido! As consequências desta carta foram muito além do que eu 
próprio esperava, pois ela correspondeu ao interesse de muita gente principalmente da esfera anglo-saxónica que me escreveu pedindo mais informações e os endereços dos poetas concretos brasileiros e de outros países de que tivesse conhecimento. A minha casa transformou-se num entreposto internacional concreto! A seguinte declaração de Don Sylvester Houédard é disso a mais inequívoca manifestação:

Pediram-me que escrevesse uma introdução ao QUADLOG para a exposição ARLINGTON - QUADRO de Poesia Concreta e trabalhos afins de poetas britânicos e portugueses e isso dá-me um prazer muito especial em primeiro lugar por causa da dívida que a poesia britânica tem para com Portugal - em 1962 o suplemento literário do "Times" no seu número de 25 de Maio publicou a carta histórica assinada por E.M.de Melo e Castro que o autoriza a ser olhado como uma espécie de figura tutelar - foi como resultado direto desta carta que Ian Hamilton Finlay e Edwin Morgan na Escócia e eu próprio em Inglaterra nos tornamos os primeiros nestas ilhas a ter consciência da importância e imensas possibilidades da Poesia Concreta - o mais recente resultado dessa carta é a presente exposição.

D.S.H. 1968

Este acontecimento complementou o trabalho realizado pelos próprios poetas do grupo NOIGANDRES, principalmente as numerosas viagens transcontinentais de Haroldo de Campos que resultaram na implantação mundial da Poesia Concreta, com a publicação de belíssimas antologias e de muitas exposições internacionais e nacionais, cursos, encontros, conferências, etc., nos mais diversos lugares e idiomas. Toda essa atividade, até fim de 1964, encontra-se descrita exaustivamente nas páginas finais de "TEORIA DA POESIA CONCRETA", de Haroldo de Campos, Augusto de Campos e Décio Pignatari, 3ª edição, São Paulo Livraria Brasiliense, 1987. Creio que seria uma boa idéia atualizar esse inventário até à atualidade.

Estes fatos documentam que a Poesia Concreta Brasileira realizou o objetivo da Poesia de Exportação proposto por Oswald de Andrade, tal como a poesia Experimental Portuguesa veio a ser o único movimento contemporaneamente internacional e em sintonia com as mais avançadas tendências estéticas e sociológicas, na poesia do século XX, que existiu em Portugal. 
ACJ: Ainda em paralelo com o Movimento Concretista, que herdou a postura militante ${ }^{1}$ presente nas vanguardas europeias do início do século XX, a poesia experimental se apresenta de forma similar. Tal como pude perceber em alguns de seus textos programáticos ${ }^{2}$, parece haver uma preocupação maior no sentido de 'educar o leitor', em detrimento de doutriná-lo, de modo que o objetivo dos textos parece incidir numa tentativa de oferecer ao leitor as bases de leitura para esse texto multimídia que você propõe. Você acredita que haja resistência de aceitação desse viés poético por parte do leitor?

EMMC: Concordo inteiramente com esta sua colocação. Eu próprio me tornei teórico e crítico com o intuito de elucidar os leitores portugueses, então totalmente despreparados e, por isso, resistentes e intoxicados por uma crítica não rigorosa chamada "impressionista" que predominava nos jornais e revistas portuguesas. Mas também para fazer frente quer ao obscurantismo da censura do regime ditatorial de Salazar tanto quanto ao pendor ideológico reducionista do Neorrealismo. Desconstruir, inventivamente os discursos opostos destes dois totalitarismos, foi sem dúvida um dos objetivos da Poesia Experimental Portuguesa, como também fora, por métodos diferentes o Surrealismo em Portugal. Este, adotando uma "ética ao contrário" e uma espécie de "mística ateia"; o Experimentalismo colocando o texto e a sua materialidade como instrumento preferencial da renovação e da invenção, o que conduziu ao uso das novas tecnologias da comunicação postas ao serviço da poesia.

$A C J$ : Atualmente, de que maneira a poesia experimental é recebida pela crítica acadêmica, especificamente, no contexto português?

$E M M C$ : Como era de esperar a recepção portuguesa aos lançamentos dos dois números dos cadernos de POESIA EXPERIMENTAL respectivamente em 1964 e 1966, foi muito polémica e nalguns casos até violenta, como, por exemplo, a troca de artigos publicados no Diário de Notícias (de Lisboa), por Manuel de Lima, (músico e crítico musical ligado ao surrealismo) e

\footnotetext{
1 Vide "Pontos-periferia-poesia concreta", "Olho por olho a olho nu", "Nova poesia: concreta" "Plano piloto para a poesia concreta", entre outros textos com teor de manifesto, que podem ser encontrados em: http://www.poesiaconcreta.com/texto.php\#

2 Vide "Uma poética do pixel", "Que olhos vêem que mundo?", “Uma transpoética 3D" (em: http://www.ociocriativo.com.br/guests/meloecastro/frames textos.htm)
} 
Jorge Peixinho, o genial compositor de 'música contemporânea' que se tinha juntado aos poetas experimentais e organizado conosco o primeiro happenning realizado em Portugal, denominado "Concerto e Audição Pictórica" com a participação de poetas, músicos e pintores, em Janeiro de 1966. Também de Jorge Peixinho foi publicado, no segundo número de Poesia Experimental, um fabuloso artigo ilustrado com propostas originais, sobre "Música e Notação Musical" considerando essas notações como poesia visual. Mas as reações adversas vinham tanto da direita como da esquerda e até de grupos sociais indiferentes às atividades das vanguardas, tais como professores do ensino médio e até universitário! Em 1915, no tempo do Orpheu de Fernando Pessoa, a acusação geral veiculada pela imprensa, era de "loucura". Em 1966 era de "abuso de liberdade de imprensa" e "anarquismo" ou coisas desse teor de incompreensão. Tais reações generalizadas atemorizaram alguns possíveis aderentes e quanto a mim estiveram na origem do posterior afastamento de Herberto Helder. Outro tanto não aconteceu com o já renomado poeta António Ramos Rosa, que colaborou em outras publicações experimentais, nomeadamente no hoje célebre Suplemento Experimental do Jornal do Fundão, de 1965, que teve larga difusão mesmo internacional. Suplemento onde também colaboraram o crítico e poeta José Blanc de Portugal, com um extenso artigo teórico e com poemas visuais os poetas Maria Alberta Menéres e Luiz Veiga Leitão cujas obras de grande qualidade poética, são apenas tangenciais ao experimentalismo. Mas o tempo passa aceleradamente e o que parece mais sólido é quase sempre o que mais depressa se dilui...É assim que depois de duas dezenas de anos de obscurecimento, durante as quais houve as mais desesperadas iniciativas poéticas de muitos jovens até ajudados por editores comerciais, quantas vezes, ancorados numa idéia de superior qualidade poética que os seus textos afinal não justificavam, surge uma geração de pseudogênios que afinal pariram apenas ratos, mesmo com a aura de elevados títulos acadêmicos, e as mais rebuscadas e nebulosas teorias da sublimidade da poesia... No entanto, uma outra ainda mais nova geração de poetas e estudiosos acadêmicos, já no presente século XXI, estão fazendo a pouco e pouco, uma descoberta interessante: a existência entre os anos 60 e 80 do distante século XX de uma poesia experimental portuguesa com características universais e propondo no deserto de então, um novo humanismo, ao mesmo tempo dinâmico e poético. É que afinal talvez seja interessante estudar o que esses poetas de há quarenta e mais anos, (alguns 
ainda vivos) disseram e escreveram. Talvez esse experimentalismo humanista possa ter sido um grito de antecipação, contendo algumas respostas e propostas que nos possam ajudar a entender o caos informativo e plural que subitamente nos envolve e confunde. Afinal, talvez a atitude desalienante desse experimentalismo, que foi eficaz perante as ditaduras fascistas de 50 e 60, seja também eficaz perante os totalitarismos das democracias fracas nossas contemporâneas que tudo medem pelo valor comercial e de lucro imediato. Talvez a poesia experimental, que não teme as possibilidades de invenção estética das novas tecnologias, contenha o antídoto dos aspectos negativos e alienantes dos produtos dessas mesmas tecnologias a que alguns teóricos chamam de "efeito de desastre"(vide Paul Virilio). Creio que é por isso que estão atualmente surgindo dissertações de mestrado e teses de doutorado que estudam as características tanto específicas e estruturais como comparativas, da Poesia Experimental Portuguesa. Talvez seja por isso que, em algumas universidades, como a vetusta Universidade de Coimbra, a Universidade Nova de Lisboa, a Universidade do Minho, assim como nas Faculdades de Belas Artes das Universidades de Lisboa e do Porto, o interesse pelo estudo da Poesia Experimental se vem desenvolvendo e aprofundando. Em Portugal, atualmente, estuda-se a Poesia Experimental também em manifestações fora das universidades que se manifestam pela organização de exposições, conferências e performances, começando a delinear-se um ressurgimento do interesse que certamente terá conseqüências positivas na própria criação poética das gerações novas. Também um núcleo de poetas experimentais que se começaram a afirmar depois de 1980 com a publicação da antologia documental POEMOGRAFIAS, Perspectivas da Poesia Visual Portuguesa, reaparece com grande força inventiva, fora dos circuitos da arte comerciável e das galerias venais, realizando exposições e eventos, ao mesmo tempo dialogando tanto com os primeiros experimentalistas ainda ativos, como com os novos poetas possivelmente emergentes. São eles, António Barros, Silvestre Pestana, Fernando Aguiar, Manuel Portela, António Nelos, Antero de Alda e outros, tendo como base, Coimbra (Casa da Escrita) Porto, Vilanova de Cerveira (Bienal) no Norte de Portugal, mas também em Lisboa com Fernando Aguiar. Todos têm vasto currículo internacional nas vias alternativas e, repito, não comerciais, o que é certamente muito significativo de uma postura de crítica desalienante, realizada através do seu original trabalho poético. 
$A C J$ : Características da Poesia Experimental foram as parcerias promovidas entre os poetas, artistas plásticos e músicos, o que favoreceu uma ideia de coletividade no ato da criação poética. Essa prática coletiva amplia as possibilidades de interferência no ato criativo, tal qual, a meu ver, o uso de mídias diversas também ampliaria. Você poderia falar um pouco sobre isso?

EMMC: Estando mais uma vez de acordo com o que acaba de expor, relembro que na Poesia Experimental Portuguesa, a par com a textualidade verbivocovisual presente nas produções literárias, estiveram sempre presentes músicos como, por exemplo, Jorge Peixinho e Jorge Lima Barreto, assim como artistas plásticos como João Vieira, António Sena, Emerenciano, Fernando Calhau e outros, fato que ficou bem claro na grande exposição coletiva chamada ALTERNATIVA ZERO, organizada em 1977 pelo cineasta e artista multimedia José Ernesto de Sousa, na Galeria de Arte Moderna em Lisboa, com a colaboração de 40 artistas, entre os quais Ana Hatherly, Jorge Peixinho e eu. É que as características de uma atitude experimental se manifestam pela abertura, a multiplicidade polivalentedos valores culturais, a indeterminação expressiva, a miscigenação dos gêneros, o poliglotismo comunicacional, o caráter risomático do saber científico e artístico, a possibilidade dos hipertextos mais variados, a abdução como regra fluida de invenção científica tanto quanto estética, a visão poliédrica e fractal... Tudo sendo simultaneamente motivos e consequências de um pensar experimental sem fronteiras, mas também de um sentir que pouco a pouco, mas rapidamente se produzirá num novo homem que vai surgir quando menos se esperar. Mas é precisamente aí que a poiesis se instala e embora o Homo Sapiens talvez se transforme em "Homo ciborgue", ele será certamente mais humano do que a nossa atual cultura já em desagregação violenta. É que a poesia contém uma resposta que hoje não está contida nos mais avançados sistemas econômicos, políticos e até culturais. Estando fora desse ainda preponderante sistema, mas já em crise de respostas e soluções, estamos perante uma situação em que se aplica o teorema de Godel que diz que num sistema fechado existem situações em que a solução se encontra fora desse sistema. Este será, portanto, o caso da invenção poética, já que a Poesia corporiza em texto e formas visuais, contraditórias ondas energéticas: que nos atacam e destroem, mas também as construtivas que 
nós, os poetas, sabemos e podemos transformar, enviando-as para os destinatários universais que as saberão, ou não, decodificar e entender lá onde quer que se encontrem e como quer que entendam aquilo que está escrito... Porque a Poesia, que se iniciou no Egito há mais de 6.000 anos com o canto fúnebre das mulheres, é por isso transcendente, isto é, está para além de tudo o que possa ser ou não ser. Passou pelos delírios das escritas hieroglíficas e ideogramáticas. Passou pelas dionisíacas folias, pelas delícias de Orfeu, pelos enigmas das pitonisas, pelos contos de Homero. Passou pelos labirintos Barrocos. Passou pela devoração dos monstros que são os inventores da escrita alfabética com seus intermináveis textos épicos renascentistas e pelos metatextos e hipertextos contemporâneos. Passou pelos rigores da expressão e pelas torturas das metáforas e o deslizar das metonímias. Passou ao largo de todos os sistemas de instrumentalização ideológica. Passou pela reinvenção do olhar e do sentir, resistindo a todas as leituras de todos os leitores em todos os suportes materiais, virtuais e sinestésicos... Porque a POESIA, essa energia inesgotável que só o HOMEM-POETA sabe engendrar e emitir, deve hoje ser considerada como o último refúgio de todas as propostas válidas para a formação do próximo paradigma do HUMANO... SEJA ELE O QUE FOR. Mas isto "há pouca gente para dar por isso" como disse Álvaro De Campos/Fernando Pessoa num pequeno poema equacionando o binômio de Newton com a Venus de Milo e o vento, isto é, a probabilística matemática, a beleza escultórica e a fluidez dos elementos naturais. Eis o poema:

O BINÒMIO de Newton é tão belo como a Vénus de Milo O que há é pouca gente para dar por isso.

óóóó---óóóóóó---óóóóóóó óóóóóóóóó

(O vento lá fora).

Por isso, repito, parece oportuno começar a tentar relacionar a natureza da Poesia com um possível novo paradigma do humano, a partir de fora dos atuais sistemas econômico e político que estão em acelerada desagregação, por falta de alternativas. Invocando mais uma vez o teorema de Godel, parece que só de fora desse sistema poderão surgir as soluções necessárias... Talvez utopicamente um sistema fora do controle econômico/financeiro, como sempre foi o sistema poético, ou seja, as tarefas paradoxais, 
impossíveis, idealistas, mas profundamente humanas, como por exemplo, dizer o que não pode ser dito, sentir o que está para além dos sentidos, pensar o que nunca se pensou, inventar o novo (que é o que ainda não existe) comunicar o incomunicável, e outras tarefas impensáveis, mas que desde há muito têm sido consideradas como tarefas dos poetas. Não dos poetas escrevedores de versos para dizer o já dito, mas para dizer probabilisticamente o que nunca o foi. Este é certamente o resumo de um projeto urgente de agoridade, para uma nova pedagogia da invenção e da cultura desalienada, ou seja, dos pilares da necessária renovação da educação e do conhecimento, se quisermos sobreviver e viver bem no mundo que se anuncia e se aproxima, vencendo as dificuldades e carências do presente. Ou seja, num mundo de cadáveres resultantes das guerras, carnificinas, catástrofes, terrorismos e absurdos vindos dos séculos XIX e XX, mas ainda atuantes no agora, pelas suas consequências negativas. Trata-se, portanto, e em primeiro lugar, de remover escombros e ao mesmo tempo criar um novo humanismo para uma época que apenas se adivinhava nos últimos anos do século $\mathrm{XX}$, mas que hoje tem a pressão da possibilidade, pela rápida evolução das tecnologias de comunicação, das ciências biogenéticas, dos métodos científicos de produção e distribuição dos alimentos e de uma urgente economia sem exploração financeira, mas com a perspectiva de debelar os males que ainda hoje nos afligem, preparando-nos para viver dignamente num mundo de 9 bilhões de habitantes ou ainda mais. Esta perspectiva otimista, baseada tanto em valores de liberdade como de conhecimento e tolerância, contem as razões e porventura os meios, para a recriação de uma forma milenar de invenção e de uma nova fruição estética a que continuaremos a chamar de POESIA, talvez por mera teimosia... Mas agora cada vez mais equipados tanto com fatores e instrumentos tecnológicos, como de valores filosóficos, numa sociedade que, por ser complexa, não pode prescindir desses valores e conteúdos por mais contraditórios ou impossíveis que nos pareçam. Não podemos nem devemos por isso, esquecer o que o poeta romântico inglês PERCY BYSSHE SHELEY (1792 - 1882), contemporâneo de Goethe, disse no seu famoso ensaio "DEFESA DA POESIA":

UMA DAS TAREFAS DO ARTISTA É ABSORVER O NOVO CONHECIMENTO DAS CIÊNCIAS, É ASSIMILÁ-LO PARA AS NECESSIDADES HUMANAS, COLORI-LO PARA AS 
PAIXÕES HUMANAS, TRANSFORMÁ-LO NO SANGUE E NOS OSSOS DA NATUREZA HUMANA.

Mas, no entanto, as fugidias passagens por todos os infernos e paraísos alucinógenos de Dante, de Camões na Índia e na Ilha de Moçambique, de Ângelo de Lima ou de Ezra Pound no hospício, ou das "câmaras de gás" nos nossos lugares de trabalho, dos desassossegos de Fernando Pessoa, ou nas latrinas pútridas junto às nossas higiênicas cozinhas eletrônicas, ou das violências dos nossos lazeres urbanos, ou das escolas de tiro para crianças menores (nos USA), tudo isto só é comparável ao menos mau dos textos que diariamente lemos nos jornais e das repetitivas imagens da TV, onde são depositados os ovos venenosos das opiniões dos comentaristas de todas as políticas dando voz à irresponsabilidade globalizada dos gases venenosos que começam a substituir o oxigênio da nossa respiração, afogados que estamos em quilómetros de cordões umbilicais inúteis porque podres.

ACJ: Lembro-me de ter assistido a uma comunicação na Casa das Rosas, por ocasião do lançamento de sua plaquete Quatro Cantos do Caos, na qual você mencionou que um dos versos do poema resultou de um 'erro acolhido' (lembro-me ainda de você ter falado qualquer coisa sobre não saber precisar se o 'erro' era decorrência da sua digitação ou da diagramação do livro): a interferência da mídia contribuindo na geração do poema. Você poderia falar mais sobre esse verso, em particular, e sobre eventuais interferências ou 'erros acolhidos'?

EMMC: Não se trata de um verso que contém um erro ou vários erros que eu não emendei. Trata-se de algo mais complexo e poético que vou relatar. Esse poema compõe-se de quatro partes a que chamei Cantos. Foi quase todo escrito diretamente no computador, mas no terceiro Canto a luz solar que entrava pela janela, começou a diminuir de intensidade porque era ao anoitecer. Eu continuei a digitar o poema até ficar quase sem luz. Como sou um mau digitador comecei a fazer erros sem dar por isso, trocando letras, pondo letras indevidas, pondo letras a mais etc... Mas, em vez de corrigir essas perturbações létricas, eu admiti-as como neologismos e contribuições do acaso que se manifestou através da luz solar. Esse trecho do poema foi, portanto, escrito com a colaboração do sol poente! A diagramação não foi 
alterada e foi conservada a estrutura estrófica de tercetos de rima branca. O quarto Canto é um sintético poema visual.

ACJ: Ao final dos Quatro Cantos, nos "Parágrafos posteriores", lemos a seguinte advertência: "O autor também não sabe em que momento desse ciclo a escrita aparece a negro sobre o branco do papel ou da tela do computador e sob que formas as letras formam ou disformam as palavras, e o que elas inevitavelmente dizem". Creio que seja possível ler esse trecho em consonância com a ideia de realce da possibilidade interventiva resultante do uso das mídias no ato criativo, na qual insisti até agora. Se estou certa quanto a isso, você concorda que a figura do autor, centrada num eu/indivíduo, único responsável pela obra - tal como é encarada em grande parte da produção lírica portuguesa - é colocada em questão?

EMMC: Sim, concordo! O eu chamado lírico é claramente posto em questão em toda a produção poética realizada com meios tecnológicos. Isto aparentemente é verdade, mas a primeira observação que se deve fazer é que "a figura do autor centrada num eu/individuo" tal como diz, não me parece que seja afetada ou posta em causa. Muitas vezes me fizeram já esta pergunta: na infopoesia onde fica o eu do autor? Ao que eu sempre respondi: o eu do autor fica onde sempre esteve, isto é, no interior desse autor... Mas é claro que é preciso que esse autor tenha um EU, o que nem sempre acontece... É preciso, portanto, distinguir o "eu poético" (figura apenas da retórica literária) do "eu psíquico" do homem que escreve e que, por conseqüência, ganha uma qualificação de autor. Talvez por isso Fernando Pessoa escreveu que 'o poeta é um fingidor', pois o que o 'eu poético' escreve nos poemas pode e talvez deva não coincidir, por razões da própria estética e natureza da escrita poética, com o que o "eu psíquico' sente ou pensa. Isso é do seu foro íntimo e pode servir quando muito de estopim para que a escrita se inicie. A escrita do poema é em si própria um princípio e um fim, quaisquer que sejam os meios e técnicas que o poeta use. Mas também esse autor pode usar várias tecnologias de escrita: lápis, caneta, máquina de escrever, pincel, carvão, penas de aves aguçadas e até os seus próprios dedos, sobre variadíssimos suportes, etc. Com cada um desses meios é obvio que ele fará uma escrita diferente e, por isso, um poema diferente. Lembremo-nos do que disse já há muitos anos, Marchal Mac'Luham: "o meio é a mensagem"! Por isso os infopoemas feitos no 
computador, por exemplo, com o programa Photoshop, só podem ser obtidos como resultado da coordenação triangular do poeta-operador, do computador e desse programa. Os três numa sinergia perfeita, mas só o poeta-operador tem capacidade de comando das operações e de crítica dos resultados obtidos. No entanto os resultados do trabalho inventivo realizado tecnologicamente exibem características estéticas que marcam de um modo indelével a percepção que temos deles. A esse fenômeno pode chamar-se tecnopoiesis (v. o capítulo "Tecnopoiesis - que futuro para a poesia?" nas páginas 209 e seguintes do meu LIVRO DE RELEITURAS E POIÉTICA CONTEMPORÂNEA, Belo Horizonte, Veredas e Cenários, 2008).

ACJ: Esse mesmo empenho coletivo diante do ato criativo está presente entre os integrantes do movimento surrealista que, no caso de Portugal, redundou numa série de poemas e textos de caráter programático e escritos não apenas mediante a prática do cadáver esquisito - muito pautado pelo automatismo psíquico -, mas por meio de uma série de procedimentos (ou jogos, tal como propunham os surrealistas) que, em alguma medida, se assemelham à prática criativa dos poetas experimentais, como a colagem, o processo combinatório dos vocábulos, o apelo à visualidade, e outros. Como resultado, tanto poemas surrealistas quanto poemas experimentais acabam por ampliar a possibilidade de leitura que, como afirma Maria de Fátima Marinho, não mais linear, se torna dinâmica e plural. Considerando as semelhanças e as diferenças entre um e outro movimento, você considera que houve diálogo entre poesia surrealista e poesia experimental?

EMMC: Certamente esse diálogo existiu e era inevitável, pois ambos coincidiram no mesmo espaço cultural com alguma sincronicidade temporal, embora defasados. O Surrealismo iniciando-se efetivamente em Portugal no fim dos anos 40 prolongou a sua influência até à década de 60 . A Poesia Experimental começando no final dos anos 50, por autores individuais com diversas formações e práticas poéticas já afirmadas, tem 0 seu apogeu na década de 60 com a publicação já referida dos cadernos de Poesia Experimental, mas sendo ainda ativa na década de 80 tem hoje a sua influência e reavaliação estendida a gerações mais novas. No entanto nunca houve um grupo experimentalista nem sequer um manifesto coletivo. Houve e há uma posição experimental que não se perdeu, antes se 
desenvolveu em obras individuais de cada um dos participantes desses cadernos e outras publicações coletivas, como HIDRA e OPERAÇÃO, ambas de vida efêmera programada, mas da mais absoluta vanguarda. Esse diálogo entre Surrealismo e Experimentalismo assumiu por isso um caráter também individual, não se podendo estender a todos os poetas experimentais nem a todos os poetas surrealistas. Pode dizer-se que tínhamos em comum a Língua Portuguesa, mas até a situação social e política dos anos 40/50 em que o Surrealismo se desenvolveu em Portugal, já não era a mesma do final dos anos 60 e na década seguinte em que o Experimentalismo apareceu e se desenvolveu. Nos anos 50 a cultura em Portugal tinha dois intérpretes dominantes: o regime ditatorial de Salazar e os seus opositores Neorrealistas. Eram estas as forças instituídas contra as quais os Surrealistas tinham que lutar em prol da Liberdade da vida e da expressão. E fizeram-no com grande eficácia e invenção poética. Nos anos 50, o Surrealismo era uma atração inescapável para os jovens. Eu também não resisti a essa tentação. Mas, no decorrer dos anos 60, a situação política foi mudando em Portugal e no Mundo exterior. Em Portugal a guerra nas colônias de África devastava a economia portuguesa a estropiava e matava os jovens portugueses, ao mesmo tempo que o regime se ia enfraquecendo e por isso atiçando a censura à informação e à criação literária. Por outro lado os novos meios de comunicação iniciaram o seu apelo e de fora chegavam impulsos democráticos e de inovação social e econômica. A Europa tornou-se um polo de atenção e até de sedução. E foram essas as razões intrínsecas e extrínsecas do aparecimento da oposição experimental. Mas agora, no plano interno, era preciso enfrentar a hegemonia do Surrealismo, a incompreensão do Neorrealismo e a censura feroz da ditadura que se apoiava num nacionalismo caduco e nos preconceitos da religião católica. Enquanto o Surrealismo se consolidava culturalmente e desenvolvia com aspetos locais sob a forma de um Abjecionismo militante, mas também moralista (ao contrário), o experimentalismo ganhava foros de perigoso internacionalismo e desempenhava o papel certo de uma vanguarda esclarecida, mas minoritária. É certo que todos nós nos conhecíamos uns aos outros e nos reconhecíamos num inimigo comum: a inviabilidade da ditadura que mantinha a guerra em África e que impedia a liberdade e o desenvolvimento económico e social, através de um discurso obsoleto que era preciso desmascarar. Foi essa uma das lutas realizadas pelo 
experimentalismo e que hoje ainda, passados tantos anos, lhe garante a sobrevivência perante as novas ameaças de uma democracia de fachada e uma ditadura dos meios econômicos impostos tanto pelo neoliberalismo e seu capitalismo financeiro selvagem que só provocam desequilíbrio e desemprego na União Europeia e instabilidade política nos Estados Unidos da América, agora, estendendo-se também aos chamados países emergentes, China, Índia, Rússia, dos quais o Brasil começa felizmente a se diferenciar privilegiando o crescimento dos fatores humanos e não se preocupando muito com o crescimento econômico anual! Mas voltando aos aspetos poéticos sei, por experiência própria, que os Surrealistas Portugueses não gostavam das interferências do Experimentalismo e que só na poesia de Alexandre O'Neill e Mário Cesariny se podem encontrar algumas interferências e correspondências com a Poesia Experimental, nomeadamente com a Poesia Concreta e posteriormente com o virulento tratamento epigramático da linguagem poética praticado por O’NEILL. Uma interessante e bem estruturada Dissertação de Mestrado foi recentemente apresentada na Faculdade de Ciências Sociais e Humanas da Universidade Nova de Lisboa por Sara Lacerda Campino com o seguinte tema "O Experimentalismo na obra de Alexandre O'Neill", trabalho inovador que tive o prazer de acompanhar e discutir no seu desenvolvimento. Quanto aos métodos usados, o chamado cadáver esquisito é típico dos Surrealistas e, segundo creio, nunca foi usado pelos experimentalistas. Mas as técnicas de colagem foram usadas por surrealistas e experimentalistas embora de modo completamente diferente. Considerese como exemplo os poemas encontrados de António Aragão (poeta experimental) que recortava aleatoriamente palavras e pedaços de texto dos jornais colando-os segundo critérios puramente visuais e plásticos em suportes rígidos. Seguidamente, efetuava leituras várias e aleatórias do que estava escrito nessas colagens assim construindo poemas experimentais inesperados. Cada colagem podia assim dar origem a muitos e variados textos que eram transgressivos pelo seu próprio caráter aleatório, colocando problemas de leitura e de inteligibilidade, tipicamente experimentais. Deve ser acrescentado que essa proposta de António Aragão foi objeto de tratamento digital pelo Projeto CETIC, dirigido por Rui Torres na Universidade Fernando Pessoa, no Porto. Pelo seu lado os surrealistas organizavam as suas colagens de modo a elas constituírem textos de acordo com um nexo literário subversivo pré-existente, pois 
selecionavam os recortes e escolhiam a sua colocação no espaço do suporte, a cada colagem correspondendo apenas um texto. Se entro nestes pormenores técnicos é porque os considero como exemplificativos de duas maneiras diferentes de conceber e elaborar a invenção literária.

ACJ: Entre 1964 e 1966, você, Antonio Aragão, e Herberto Helder se encarregaram da organização da revista Poesia Experimental nº 1 e n⿳0 2. Chama atenção o fato de que, além de Herberto Helder, outros poetas se aproximaram circunstancialmente da poesia experimental nesse momento (apenas para citar alguns nomes: Antonio Barahona, António Ramos Rosa). Por qual motivo você acredita que essa aproximação se deu apenas de forma pontual?

EMMC: Sim! Creio que sim! António Barahona da Fonseca era, em 1964, já conhecido como poeta possivelmente pós-simbolista e místico que, no entanto, frequentava a roda de poetas que viriam a ser os organizadores e colaboradores primeiros dos cadernos de Poesia Experimental: António Aragão, Herberto Helder, Sallete Tavares, Melo e Castro, Ana Hatherly. Quando ele apareceu com um poema organizado segundo um critério alfabético, mas com características inovadoras, foi facilmente aceito como um jovem colaborador. Mas esse pendor não durou muito e a sua poesia de grande interesse e originalidade, continuou a se desenvolver até aos dias de hoje, mas sendo sempre um companheiro dum experimentalismo que não pratica. Quanto a António Ramos Rosa ele foi considerado desde cedo, isto é, desde o final dos anos 50, como uma ponte entre o neorrealismo e algo que veio a ser o experimentalismo que nessa altura já estava em elaboração teórico-criativa através da Revista ÁRVORE (de que com Raul de Carvalho foi diretor), propondo uma atitude de redução fenomenológica inovadora que considerava a realidade como estando lá, mas da qual o poeta só se apercebia pela sua subjetividade. Assim se distanciava do Neorrealismo programático e ideológico, abrindo caminho para uma poesia em que os meios de elaborar essa percepção oblíqua e individual passavam necessariamente pela valorização dos aspectos textuais do próprio poema. Dessa posição à proposta experimental foi apenas um salto abdutivo! Por isso Ramos Rosa era por alguns de nós considerado um mestre. Um outro caso curioso são as oscilações entre o experimentalismo e o surrealismo do poeta José Alberto Marques, cuja ambigüidade e 
instabilidade são um traço experimental inequívoco, sendo autor de inspirados e originais poemas visuais e conceptuais que por vezes se aproximam do Poema Processo Brasileiro que ele, no entanto, só tardiamente conheceu. Muito interessante foi a colaboração no segundo número de Álvaro Neto, pseudônimo de Liberto Cruz, com poemas violentos de desconstrução do discurso oficial da ditadura, baseados nos princípios da Gramática Histórica. Verdadeiramente casual e pontual foi a colaboração de Luiza Neto Jorge já então considerada como líder de um outro grupo de poetas muito mais jovens que os experimentais, que tinha publicado um conjunto de plaquetes sob o nome geral de POESIA 61. Esse grupo que não considerava a poesia visual como Poesia, também se afastava da proposta complexa verbivocovisual e embora fosse inovadora a sua posição ela revelou-se incompatível com qualquer tipo de experimentalismo. No entanto representa um diferente caminho textual/semântico que veio enriquecer a poesia portuguesa da segunda metade do século XX.

ACJ: As suas duas últimas publicações: Neo-Poemas-Pagãos e O paganismo em Fernando Pessoa e sua projeção no mundo contemporâneo, embora resultem de impulsos diferentes (no primeiro caso, a criação literária; e, no segundo, a pesquisa acadêmica), incidem ambos sobre a questão do paganismo e, mais enfaticamente, sobre o paganismo como manifestação da atualidade: o neopaganismo. Tal como você propõe no seu estudo teórico sobre Pessoa, o neopaganismo seria uma manifestação das relações entre ciência e arte promovida pelos tecnólogos, "relações estas que consistem na produção de novos mitos, que não poderão culturalmente deixar de estar relacionados com os velhos mitos greco-latinos (...)". Você considera que esses novos mitos já fazem parte do imaginário literário da atualidade?

EMMC: Sim, parece-me que sim. Do meio literário e social. Os novos mitos estando ainda em formação estão já presentes no imaginário de agora, a que gosto de chamar a agoridade porque essa agoridade sendo efêmera é também polivalente e incorpora a abertura e a mudança de um modo problemático e probabilístico, ou não fosse ela trabalho de engenheirospoetas ou de poetas-engenheiros! No entanto o panorama é ainda perturbado pelo ruído da derrocada do modelo economicista, arrastando consigo a crise dos modelos político e ideológico, num mundo globalizado 
e fazendo com que os extraordinários avanços tecnológicos sejam valorizados principalmente pelos seus aspectos negativos, como, por exemplo, a Internet e as redes sociais de comunicação. Assim arriscamonos a entrar no vazio da razão e da vida civilizada... Já o poeta de Alexandria Konstantino Kaváfis dizia, no final do século XIX, que os bárbaros estavam chegando, mas que, apesar de todos os preparativos e expectativas, eles não chagaram porque não existiam... E "sem bárbaros o que será de nós? Ah! Eles eram a solução". Assim parecem estar novamente os poderes que governam o mundo, esperando que os bárbaros lhes tragam as soluções nos moldes desejados, isto é, ficando tudo na mesma ou cada vez pior. Mas estes novos bárbaros têm agora outros meios e outras soluções diferentes, tal como no decorrer desta entrevista tive a ocasião de referir. Os novos bárbaros somos nós os ciberpoetas. Seremos?

ACJ: Tendo em vista o diálogo entre a epígrafe de Neo-Poemas-Pagãos ("os deuses não são pagãos/ pagãos somos nós/ que vivemos no seu desconhecimento/ e acreditamos que podemos/ conhecer-nos") e os poemas contidos no livro em questão - alguns deles, como é o caso da série "Transvisuais", demonstram claramente esse viés tecnológico -, nota-se que as indagações sobre o conhecimento de si incluem as esferas científicas do saber instituído (reflexões sobre o sujeito associadas ao tempo, ao espaço, à matéria e ao próprio fazer poético). Você poderia falar mais demoradamente sobre esse tópico?

EMMC: O enunciado desta sua pergunta, se eu a entendi bem... Parece-me que contém as respostas possíveis. Talvez falar mais sobre este tópico será cair em redundâncias desnecessárias, pois me parece claro que o neopaganismo, por que Álvaro de Campos clamava anunciando a sua próxima chegada, instalou-se entre nós sem que a maioria desse por isso, apenas aceitando os benefícios superficiais e imediatos que as novas tecnologias vendidas pelos capitalistas, lhes ofereciam. Por isso não tomaram as devidas cautelas quanto ao nefasto efeito de desastre que é o preço que os novos deuses exigem aos homens. Ora, acontece que esses homens ignorantes (nós) "tomamos as nuvens por Juno" quando confundimos os avanços tecnológicos tomando-os como sendo os novos mitos e os instituímos como sendo os novos deuses. Deuses que, no entanto, continuamos a ignorar, enquanto buscamos conhecermo-nos a nós 
próprios nas ilusórias imagens virtuais que esses mesmos meios tecnológicos nos oferecem. Torna-se assim evidente que o saber instituído como cultura entra em curto circuito ao tentar desesperadamente sobreviver num mundo virtual que vai tomando conta de todas as veleidades de autoconhecimento pelo já arcaico aprofundamento subjetivo ou análise psicológica. O mundo será dos ciborgues que nós próprios já estamos a começar a ser quando simplesmente usamos um sofisticado telefone celular ou um computador como este que eu estou usando para produzir este texto. Mas os ciborgues terão identidade baseada na subjectividade?

$A C J$ : Há pouco tempo você esteve em Coimbra para a montagem e inauguração do seu mais recente trabalho videopoético. Poderia falar um pouco sobre isso (concepção, recepção, etc.)?

EMMC: A Casa da Escrita, em Coimbra, que é uma instituição cultural da Câmara Municipal, funcionando tangencialmente à Universidade, decidiu organizar um ciclo de exposições (comissariado por Jorge Pais de Sousa) do trabalho contemporâneo de sete poetas experimentais portugueses, numa perspectiva não historicista, mas, sim, da plena agoridade que esses experimentalistas encarnam e representam. Assim, cada um desses autores foi convidado para expor livremente as suas mais recentes propostas experimentais, colocando também a noção de experimentalismo em questão. O título deste ciclo é "Nas escritas PO.EX". Fui convidado a fazer a primeira exposição que foi inaugurada no dia 3 de Outubro passado, e esteve aberta ao público durante pouco mais de um mês. Seguiu-se a exposição de Antonio Barros sob o tema PROGESTOS/OBGESTOS e no próximo dia 8 de Janeiro será inaugurada a exposição de Silvestre Pestana com o título POVO NOVO VIRTUAL. Os outros poetas serão Manuel Portela, Jorge Lima Barreto (homenagem póstuma), Fernando Aguiar e Ana Hatherly. No final do ciclo será publicado um livro reunindo as propostas dos participantes. Esta iniciativa, que também inclui palestras, visitas e encontros para discussão dos trabalhos expostos, não tem qualquer intenção comercial e ilustra, reforçando-a, a criação de novos modos de encarar as relações entre a cultura instituída e a produção de propostas artísticas, transgressivas e experimentais de poetas que nunca foram, nem quiseram ser assimilados pelo chamado sistema das artes. Por outro lado manifesta e expõe a continuidade contemporânea da poesia experimental, 
considerando como necessárias essas escritas PO.EX. Na minha exposição, a que dei o título DO LEVE À LUZ, dei continuidade aos trabalhos apresentados em 2006 na exposição que realizei no Museu de Arte Contemporânea de Serralves, na cidade do Porto, O CAMINHO DO LEVE na qual fiz uma apresentação não cronológica, mas sincrônica do meu trabalho experimental desde a poesia concreta dos anos 60 até ao desenvolvimento do uso criativo das novas tecnologias para a geração de infopoemas e videopoemas, passando por varias fases temáticas e metodológicas. Na recente exposição DO LEVE À LUZ prossegui no mesmo caminho procurando sinalizar uma crescente desmaterialização das imagens virtuais, desde os meus primeiros poemas fílmicos dos anos 50 e 60 até novas formas de inventar videopoemas e de apresenta-los em instalações de imagens múltiplas nas várias salas de que a Casa da Escrita se compõe. Houve assim uma tentativa de integrar a arquitetura da Casa, que não é uma galeria de arte, com as imagens virtuais dos catorze novos videopoemas que realizei para esta exposição. Pelos corredores e escadas espalhei impressões de infopoemas e textos teóricos, que foram também guias dos percursos a percorrer. Apresento agora um desses textos:

\section{A EXPLOSÃO DOS PARADIGMAS}

O meu trabalho de invenção há muito tempo que nada tem a ver nem com as artes plásticas nem com a poesia lírica, embora utilize formas, cores, letras e palavras para dizer coisas que nada têm a ver com as coisas que se dizem com palavras, letras, cores e formas. O que invento e chamo de poemas, o que invento e chamo de objetos, não são nem poemas nem objetos. Por isso comecei por qualificá-los como objetospoemas ou como poemas-objetos... mas que agora desqualifico na procura de alguma coisa outra, tal como o LEVE DE NÃO SER e a LUZ DE SER como matérias do fazer. Dos átomos da matéria até ao leve dos imateriais, há todo um trajeto que se pode entender, pois se trata de conceitos que estão em jogo. Conceitos são pensamentos. Mas dos conceitos imateriais à LUZ há toda uma envolvência de energias que se vêem e se podem sentir, pois se trata de emoções, sempre totais e complexas como uma simples iluminação. É disso que tratam os meus atuais vídeos seriais.

Para concluir, penso que posso dizer, sem falsa modéstia, que a exposição foi muito visitada e recebida geralmente com muito interesse e curiosidade 
principalmente por estudantes universitários (que predominam em Coimbra) tendo realizado duas entrevistas com perguntas pertinentes procurando um entendimento mais detalhado das minhas propostas experimentais.

\section{Licença: (c) (i) ():}

Concepção e realização da entrevista:

Ana Cristina Joaquim

Pós-doutoranda na Universidade Estadual de Campinas. Doutora egressa do Programa de PósGraduação em Literatura Portuguesa da Universidade de São Paulo.

Contato: wiquen@gmail.com

(D): https://orcid.org/0000-0002-7227-0195 